REVISTA ANDALUZA DE ANTROPOLOGÍA.

NÚMERO 2: PATRIMONIO CULTURAL Y DERECHOS COLECTIVOS.

MARZO DE 2012

ISSN 2174-6796

[pp. 149-157]

http://dx.doi.org/10.12795/RAA.2012.i02.08

\title{
MASFERRER KAN, ELIO. Pluralidad Religiosa en México. Cifras y proyecciones. México: Libros de la Araucaria, 270 pp.
}

\author{
Iván Franco \\ Instituto Nacional de Antropología e Historia (CINAH-Yucatán). México.
}

\section{Introducción}

El proceso moderno de diversificación religiosa en México hunde sus raíces en el inicio de la etapa colonial. El choque entre el europeo y occidental mundo católico español que, por cierto, atravesaba por un espíritu renovado por el éxito de las Cruzadas, con el complejo mundo religioso indígena, pronto estuvo mediado por el poder político e institucional en esencia católico. Dio como resultado un nuevo horizonte simbólico de creencias y prácticas en donde el catolicismo y sus instituciones fueron ganando terreno sin desterrar rituales ni prácticas prehispánicas; mucho menos las estructuradas visiones del milenario mundo indígena (Assmann, 2008). Gran parte de su éxito como conquista espiritual se fundamentó en el genocidio y concomitante debacle poblacional de los pueblos nativos en menos de un siglo (Cook y Borah, 1977). Con el contacto se gestó lo que a la larga sería la diversa nación mexicana.

El convulso proceso de conquista, evangelización y dominio se complicó más con las luchas de Independencia decimonónicas. El poder del catolicismo, como religión de Estado pero sobre todo la Iglesia (IC) como institución al servicio de la Corona (o regalismo, rasgo que conserva en el 2011), luchó hasta donde pudo a partir de 1821 (Toro, 1975). La IC buscó desde esta fecha mantener una gama de privilegios que la Constitución de 1857 continuó deslindando; principalmente por su rechazo al centralismo del poder católico y a la injerencia constante de Roma en la vida nacional. Entre 1821 y 1857 conocimos 
a las dos primeras generaciones de la futura clase política católica, propiamente dicha, de la historia moderna de nuestro país (Ibid.). El fusilamiento de Maximiliano signó la derrota de la Iglesia católica a largo plazo pero no su ausencia ni influencia de la sociedad ni en la cultura, como vemos, hasta el presente.

\section{I) Separación formal, amasiato real}

México es hasta la fecha el único país latinoamericano cuya ley máxima separa formalmente los asuntos del Estado de las Iglesias. El primer ciclo del modus vivendi en México, si me permiten la analogía, se desarrolló en el Porfiriato. Parafraseando al ex delegado apostólico Gerónimo Prigione se puede decir que es en esa etapa cuando empezó el "amasiato" entre Estado e IC en México. Entonces se evidenció que la jerarquía de la IC, aunque califica como "accidente histórico" al liberalismo mexicano y como herejes jacobinos a sus representantes, terminó fungiendo como estructura de poder al servicio del nuevo Estado oligárquico; subordinándose al poder político dictatorial encarnado en la figura del héroe de Tuxtepec y militar relevante del propio juarismo, Porfirio Díaz ( Romero de Solís, 1994).

Un fuerte núcleo de jerarcas tradicionales, con uno que otro liderazgo disidente, también pintaron con su actuar pro-oligarca y nacionalista, a la Iglesia Católica mexicana (Menéndez Rodríguez; 1995; Romero de Solís, 1994) desde entonces, sus “actualizaciones” terrenales antes que las pastorales están más sujetas a los intereses del Estado (por ejemplo bajo el callismo, el cardenismo o el salinismo) que ¿signo autoritario? a coyunturas específicas acordadas en la Santa Sede (Ibidem); actuación por cierto alentada y aprobada por la Santa Sede a la IC mexicana. Esto pese a que desde fines del siglo XIX la Rerum Novarum marcara un nuevo rumbo pastoral al acercar a sectores de la Iglesia mexicana a muchos de los nuevos actores económicos y políticos del capitalismo periférico de fines del siglo XIX: obreros, campesinos, artesanos, y demás (Romero de Solís, op. cit.). Como han revelado los estudios sobre Marcial Maciel y sus nexos con la política mexicana: acordando rumbos y conductas jerárquicas por encima (o aval tácito) de la Conferencia del Episcopado Mexicano y la misma Santa Sede. Ese es el signo con que transita, por decir lo menos hasta nuestros días.

\section{II) La diversidad incómoda}

Una nueva era de diversidad religiosa occidental se inauguró entonces al finalizar el siglo XIX, después de que los liberales juaristas metieron cuña al catolicismo romano dando la bienvenida a los ahora llamados "hermanos separados". Esa diversidad, sobre todo en el rubro estadístico, borró sólo en el papel la diversidad religiosa indígena de esencia prehispánica (adquirieron el status de esclavos, acasillados, peones católicos, etc.) hasta que la antropología mexicana post-revolucionaria redescubrió el "campo religioso" indígena que sobrevivía en el aún visible mundo rural. La nueva diversidad (recogida 
en 10 credos de origen europeo, asiático, hindú y las religiones norteamericanas) fue precisamente marcada o descrita en el Censo de 1895 aunque, como analiza Elio Masferrer Kan en la obra que presentamos, tuvo más carácter simbólico que real ${ }^{1}$.

Una de las aportaciones más relevantes del trabajo de Masferrer es que, pese a la contundencia ascendente del fenómeno de la pluralidad religiosa, nos revela que se le trata desde espacios y grupos de poder como una diversidad incómoda y en algunos casos como realidad "alarmante". Masferrer aclara que una de las señales que apuntan a intentar "frenar" tal incremento, en un ánimo por demás pre-moderno, es la vigencia dentro de las instituciones de gobierno de México (caso INEGI) de retorcidos criterios y sesgados métodos censales. La actitud quizá responde, pese a sensibles avances, a la reconfiguración de nuevos espacios de intolerancia en ese juego de retraimientos imantados conformado por las cíclicas interacciones autoritarias del Estado con la Iglesia Católica.

¿Qué podemos entender con el concepto de espacios cíclicos autoritarios? Básicamente la recomposición y mimetización pragmática y recurrente que se produce entre capas y elites dirigentes civiles con el catolicismo, visibles hoy día con no pocos grupos empresariales y miembros del PRI, PAN y demás partidos políticos; en donde han tenido protagonismo extremo como aliados connaturales líderes de la Teología de la Prosperidad como Marcial Maciel, del Opus Dei, la misma CEM y neoliberales salinistas y panistas. Y ¿cómo operan? Poniendo, quitando y "acomodando" obispos u arzobispos con singular alegría en lugares estratégicos para uno u otro fin político-terrenal (Franco, 2009). En conjunto esos "pactos" parecen ser los puntos que activamente están "orientando" los criterios y conceptos de altos burócratas institucionales; un fenómeno que por cierto también incide en el alcance metodológico de no pocos cuerpos académicos y en la misma sociedad como sugiere la obra de Masferrer.

Por espacios cíclicos de intolerancia entiendo también ese juego tipo bisagra, por períodos sangrientos sin ninguna duda, de acercamientos y distanciamientos acaecidos entre dirigentes del Estado liberal y/o nacionalista (Porfirio, Calles, Cárdenas, y demás) con la Iglesia católica y con el nacionalismo católico en aras de credibilidad, legitimidad y estabilidad política². Así, bajo la actual etapa de democracia corrompida, en la que

1. El catolicismo se mostró en las cifras oficiales de 1895 a 1910 como la religión única en el país con su 99.11\% del primer año, sus $99.5 \%$ de 1900 y 95.2\% del último, el que vio caer la dictadura. Con la Revolución se inició una espiral favorable a la diversidad social, lo que desde luego se hizo extensivo al universo religioso.

2. Este discurso se expresó con lujo de detalle y aspiración política en la Carta Pastoral del Encuentro con Jesucristo a la Solidaridad con Todos siendo signada por la Conferencia del Episcopado Mexicano en 1999 y cuya lectura sucinta recomiendo por enésima vez; fue publicada precisamente poco antes de que el neoliberal católico Vicente Fox triunfase en las elecciones del año 2000. 
coincidentemente el manoseo de los números y criterios estadísticos tipo IFE también jugaron su parte, muestra que en los otrora partidos liberales y en no pocas decisiones de la izquierda partidista se opta por cabalgar en sentido inverso pero pragmático al título de la carta pastoral de los obispos mexicanos de 1999. Sin despegarse de la factura y significado del voto clientelar religioso.

La práctica del PRI y en no pocos casos del PRD, ni se diga del PAN, evidencia la adopción mustia de una fórmula pública que va de la idea de impulsar "Solidaridad con todos hacia el Encuentro con Jesucristo", sin reparar en la contención política y jurídica del laicismo. Como se sabe, la sucesión de irregularidades electorales y pactos políticos que llevaron a la presidencia de la República a Carlos Salinas de Gortari en 1988, lo obligaron a emprender como titular del poder ejecutivo una serie de acciones para asirse de credibilidad y legitimidad. Uno de los capítulos que Salinas de Gortari impulsó para alcanzar autoridad política fue la reforma legal de las relaciones entre el Estado y las Iglesias; esta alcanzó su punto reglamentario el año 1992, aprobándose por mayoría la propuesta presentada por legisladores del PRI (García Ugarte, 1993; Sánchez Medal, 1992; González Schmall, 1994)³.

Un tanto insatisfechos por su alcance, algunos representantes eclesiásticos, analistas católicos e incluso no pocos militantes del PAN plantearon entonces que la reforma de las relaciones del Estado con las Iglesias se había quedado corta (Ibid.). Y como en los casos de Guadalajara, Guanajuato, Yucatán, entre otras entidades, han desplegado tácticas de reposicionamiento social y jurídico de la religión católica. En los hechos se puede preguntar en consecuencia ¿La actuación de no pocos sectores de la clase política, o por ejemplo los juicios de algunos magistrados de la Suprema Corte de Justicia, se ha encargado de probarles que no?

\section{III) ¿Reforma o aceite para la bisagra?}

A partir de la reforma de 1992, y pese a que las nuevas normas en la materia son relativamente puntuales respecto al papel acotado que deben observar las Iglesias y sus miembros en la vida pública, el protagonismo público e imposición de criterios de las jerarquías católicas en temas civiles como la promoción y orientación del voto, el aborto, los matrimonios entre personas del mismo sexo, correrías públicas con gobernantes locales y demás -en particular en entidades con fuerte cultura religiosa política e institucional católica- están a la orden del día. Han rebasado las expectativas de todos

3. La reforma de la relación con las Iglesias se concretó simbólicamente cuando Salinas de Gortari recibió al Papa Juan Pablo II en Izamal, Yucatán, en agosto de 1993; la visita papal tuvo como anfitriona a la entonces gobernadora Dulce María Sauri Riancho y fue la tercera del Papa polaco a México. Un estudio que plantea que con la reforma de 1992 México entró en camino de deslaicización del Estado en Jorge Enrique Precht Pizarro, "La Laicidad del Estado en Cuatro Constituciones Latinoamericanas", Revista Estudios Constitucionales, noviembre, año/vol. 4, número 002, Santiago de Chile, pp. 701-705. 
los actores sociales, intimidando a la clase política y cerrando espacios a la difusión en medios masivos, con todas sus implicaciones, a temas como el que nos reúne en este momento.

Hoy, después de que el PRI ha recuperado parte del terreno perdido en las elecciones del año 2000, empresarios, grupos y sectores fuertemente identificados con el catolicismo y el nacionalismo católico, nutren las bases de su militancia y promoción (Teletón por delante); en no pocos casos, postulados de este credo religioso son usados como referentes ideológicos por algunos de sus principales figuras, dirigentes y medios impresos $\mathrm{u}$ electrónicos quienes festinan por ejemplo la creación de nuevas y elitistas universidades católicas en sus entidades. Esto incluye desde luego alianzas y cercanías que políticos, gobernantes y funcionarios priistas mantienen -como capital político adicional- con las altas esferas católicas de México y con la misma Santa Sede, buscando expresa aprobación pastoral para la promoción electoral.

Si el PAN llegó a señalar que Salinas de Gortari y el PRI le "robaron" su programa de reformas económicas, quizá también podría demandar que la nueva clase política del PRI los ha desplazado del uso ¿eficiente? de algunas de sus banderas ideológicas. Una, precisamente, la adopción del discurso nacionalista católico en sus distintas variantes $y$, desde luego, adornando con tonos de brebaje proselitista y, novedad al frente, con influencia igual de sesgada en los no menos relevantes ámbitos partidista y mediático. Recordemos que diversos diputados locales del PRI, PAN y PRD impulsaron el año 2009 reformas de artículos constitucionales estatales que apuntan a criminalizar el aborto ${ }^{4}$. El punto que hoy día calienta como nunca el ambiente nacional ante los argumentos jurídicos rebuscados de cuatro de los once ministros de la Suprema Corte de Justicia.

La tendencia sigue. Según algunas fuentes, el jerarca católico de Yucatán Emilio Carlos Berlié Belaunzarán (con vínculos con la mafia de los Arellano Félix, la foto incómoda con jefes de las mafias de casinos y asesores de Felipe Calderón Hinojosa y demás), fue quien en contubernio con el ex gobernador del Estado de México, impulsaron la revolución legal en casi dos decenas de entidades confederadas en contra de leyes pro-aborto entre 2008 y $2009^{5}$; la acción encontró cierta resistencia a nivel federal con la reforma del

4. Liliana Alcántara, Se incrementan las reformas anti aborto, México, El Universal, 7 de febrero de 2010. La nota destaca que "Elsa Conde, ex diputada federal e integrante del Pacto Nacional por la Vida, la Libertad y los Derechos de las Mujeres, manifestó que de avanzar esta reforma a la Constitución se estaría vulnerando el carácter laico del Estado mexicano. Dichas reformas se han aprobado en Baja California, Campeche, Chiapas, Chihuahua, Colima, Durango, Guanajuato, Jalisco, Morelos, Nayarit, Oaxaca, Puebla, Querétaro, Quintana Roo, San Luis Potosí, Sonora, Veracruz y Yucatán, en cuyos casos prevaleció el voto mayoritario del PAN y el PRI, aunque también del PRD en el caso de Chiapas".

5. Katia D’Artigues (Campos Elíseos), Nace "República Laica". Berlié el misionero, El Universal, 27 de enero de 2010. 


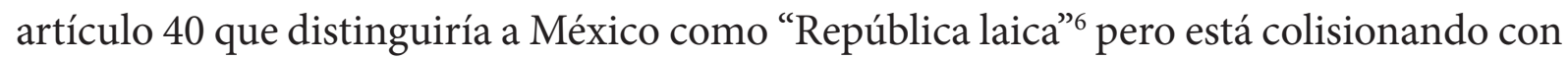
las decisiones de la SCJ. Esa tendrá que pasar la prueba de otras 16 legislaturas locales para alcanzar el rango de reforma constitucional. ¿Se puede augurar rapidez legislativa como en el caso de las primeras?

La profundidad del asunto estriba además en que la clase política pluripartidista que avaló esas reformas, junto con no pocos medios de comunicación como Televisa e infinidad de medios locales destinan horario triple A y kilómetros de páginas para resaltar esas posturas y discursos. ¿Todo el paquete indica la configuración acotada pero vigente de una corriente política nacional favorable a la instauración de un Estado confesional en plena era de la globalización, Internet y apertura mundial? ¿Saben o intuyen en los hechos, como se muestra en la obra de Masferrer, que la crisis de eficiencia de la IC lleva de por medio el cambio imparable de la sociedad tanto como la naturaleza formal y real del poder político?

\section{IV) La obra y las fuentes. Llamado a la cordura}

Masferrer muestra de forma cruda que probablemente en el 2040 la católica, en cuando menos siete entidades del norte y sur del país sería religión minoritaria, incluido el Estado de México, entidad en la que gobernaba uno de los actores de la contrarreforma (Masferrer, 2011) ${ }^{7}$. El mismo autor sostiene que católicos practicantes solo existen en México en proporción del $46 \%$, en tanto que el restante $40 \%$ de católicos son cualquier otra cosa en materia de credo y prácticas. Un analista de la misma e influyente cadena Televisa, Alfonso Zárate, expuso y criticó con lucidez la agenda de esa corriente nacional pro confesional al inicio del año 2010. Expuso, sin ofrecer datos duros, que México en cuestión religiosa y prácticas sexuales ya había cambiado y que esos grupos influyentes eran incapaces de entender el nuevo escenario de la sociedad y del país.

Ante esto Masferrer muestra cuáles serán las otras entidades con probable minoría católica en el 2040: Baja California, Chiapas, Tabasco, Campeche y Oaxaca; en todas diputados del PRI y PAN impulsaron las reformas de inspiración católica el año 2009. Esto sin contar el otro grupo de diez o más entidades en donde la relación 60/40 también evidencia la radicalidad del cambio religioso en México. Debemos por ello observar por todo lo dicho que el libro de Masferrer es un texto que desnuda con perspicacia y sobre todo con certeza científica la sustancia con que la cíclica "bisagra intolerante" Estado/ Iglesia Católica mira y actúa en este inicio del siglo XXI ante la irrefrenable diversificación

6. Elio Masferrer Kan observa que el impulso por reformar el artículo 40 se debió a iniciativa de sectores liberales masones del PRI y a figuras políticas como Porfirio Muñoz Ledo, preocupados desde luego por el rumbo y avance que han tomado las reformas locales, México, DF, entrevista realizada el 19 de mayo de 2010.

7. Las otras entidades serían Baja California Sur, Campeche, Chiapas, Oaxaca, Tabasco y casi Quintana Roo. 
religiosa. El miedo no anda en burro decían nuestros abuelos. Creo que el trabajo de Masferrer contribuye a agudizarlo.

No es el suyo sin embargo el primer acercamiento serio u ordenado al tema de la evolución de la espiral ascendente de la pluralidad de credos en México. Otros esfuerzos académicos, algunos muy notables pero otros más bien limitados o confusos en su manejo de fuentes y rigor metodológico, habían ya explorado y hasta cierto punto explicado la contundencia irreversible del fenómeno (Molina Hernández, 2003) ${ }^{8}$. La diferencia está en que el trabajo de Masferrer es un sólido análisis cuantitativo y cualitativo del proceso de pluralización religiosa. Tiene por eso el libro de Masferrer trascendencia por dos razones: a) la penetrante rigurosidad con que se acerca a las estadísticas y somete a la crítica las metodologías censales utilizadas para reportar dicho cambio en nuestro país, y b) porque lo hace a nivel nacional desglosando entidad por entidad, mediante un combinado ejercicio intelectual poco común en las obras académicas contemporáneas, los ritmos, características y proyecciones del incremento de la pluralidad religiosa.

En conjunto esas dos cualidades hacen de este nuevo material un obligado libro de consulta. Se concluye por eso después de su lectura que en la orientación o "imposición" de los "criterios metodológicos" limitados o insuficientes, tienen un papel en apariencia siniestro actores palpables en unos casos, inteligibles en otros, directamente preocupados con lo que la realidad despliega. Sugiere que irremediablemente esos criterios están incrustados en ambos casos en movimientos "administrativos" operados por actores orgánicos a la bisagra intolerante. Prácticamente ninguna fuente usada para la construcción de su discurso académico, estadístico y proyectivo sale bien librada, a pesar de que reflejan (más a disgusto en algunos casos) la cabalgata tipo "contra Cruzadas" que los porcentajes de adscripción religiosa revelan respecto a la imparable y expansiva diversidad de credos en las 32 entidades mexicanas.

No voy a atormentar con más cifras ni porcentajes que concluye y evalúa Masferrer. Consulten la obra y saquen sus propias conclusiones. Como el autor sugiere se va de lo general a lo particular y viceversa -cuando y como uno quiera- con la lectura, estudio y cotejo del texto, sus cuadros y gráficas. Resalta en mi opinión su juicio o proyección de que en menos de tres décadas la religión católica habrá perdido respecto de su primer registro moderno en 1895 casi el 33\% de su presencia en la sociedad mexicana. Esto sin contar la calidad y tiempo social que se destina al culto en la sociedad actual, parte del análisis que por cierto desde hace algún tiempo Masferrer afina obra tras obra.

La abrupta variación porcentual de católicos también se entiende como un fenómeno que responde a varios factores, tanto internos como externos al cuerpo religioso. Un estudio reciente concluye por ejemplo cómo decayó hasta en 13\% entre el año 2002 y el año 2010

8. Quien a su vez cita a quienes le antecedieron en otros intentos análogos. 
en el ánimo de la sociedad mexicana la credibilidad hacia la IC y sus sacerdotes; en gran parte, a causa de la difusión masiva de la pederastia y demás abusos a infantes ${ }^{9}$. No sé si como porcentajes son algo inédito o brutal. Habría que cotejarlo con los procesos de corta y larga duración (como el súbito descrédito en otros países) en los que la múltiple oferta religiosa (Brasil) y la exposición de las conductas perversas y criminales de uno tras otro jerarca católico (México, Alemania, Irlanda, Chile, EEUU, Bélgica, Polonia, y demás) ha impulsado a muchos sectores a salirse del catolicismo romano. Como sabemos ese proceso que encierra drama, trauma y crisis aguda ha llevado al propio Benedicto XVI a declarar que entiende "por qué muchos se estén distanciando de la Iglesia Católica".

\section{Palabras finales}

Sugiero leer sin mayor retardo la obra. Son infinidad de datos, cuadros y gráficas una y otra vez analizados con ópticas antropológicas, conceptos sociológicos y referencias históricas que, sin embargo, permiten que los datos duros fluyan y hablen por sí mismos. Se observa que algunas de las observaciones críticas de Masferrer son auténticos llamados a la ética y a la cordura metódica de la que (cada vez es más verificable), siempre han carecido con o sin voluntad expresa quienes levantan censos, encuestas oficiales y religiosas y demás herramientas estadísticas en este país para uno u otro fin.

Me parece claro que Masferrer clama porque sus llamados a la cordura conceptual a la hora de pensar y elaborar un instrumento de recolección de datos sobre "religión" y/o "creencias" se tomen en cuenta para futuros ejercicios estadísticos; oficiales o no. Su "homilía" histórico-antropológica y estadístico-proyectiva es ejemplar y de consulta obligada para todo mundo, incluidas Iglesias, no pocos sectarios, post-jacobinos, grupos de oración, grupúsculos, catequistas, monaguillos, etc. Por eso la hace extensiva para quienes realicemos esfuerzos académicos e informales en ese puntilloso mundo del cuánto y cómo se registra, lleva, practica y se traslapa en la larga duración un credo o una religión; así sea en el circunscrito campo analítico de una parroquia, una diócesis, una estaca, etc.

Sin duda estamos ante una obra que marca una forma versátil para entender el cambio de militancias, actitudes, malas sañas, y en síntesis de credos y anti credos en México pero, sobre todo, algunos de los signos más apremiantes del urgente cambio político y de actitudes más abiertas y tolerantes de las elites y grupos de poder de este país. Aporta infinidad de elementos para entender, por ejemplo, los lamentables procesos jurídicos y administrativos de endurecimiento político que hoy día está avalando el PAN y un sector de la SCJ a las oligarquías católicas locales, al mismo tiempo que da pistas para entender las etapas autoritarias de la relación Estado con las Iglesias (en particular la Católica) en

9. Carta Paramétrica. Investigación Estratégica, Análisis de Opinión y Mercado, La crisis de la Iglesia Católica, 2002-2010, En: www.parametria.com, Estrategia 360º 
contra de la ciudadanía y la democracia en sentido amplio, no de simple y manoseado ritual electoral.

\section{Referencias Bibliografícas}

ASSMANN, Jan (2008) Religión y memoria cultural. Diez estudios. Argentina: Ed. Lilmod/ Libros de la Araucaria,

COOK, Sherbune y WOODROW, Borah (1977) Ensayos sobre Historia de la Población: México y el Caribe. México: Ed. Siglo XXI,

FRANCO, Iván (2009) El PRI y sus obispos. El caso Berlié. México: Ed. Libros de la Araucaria.

GARCÍA UGARTE, Martha Eugenia (1993) La nueva relación Iglesia-Estado en México. Un análisis de la problemática actual. México: Nueva Imagen.

GONZÁLEZ SCHMALL, Raúl (1994) Reformas y libertad religiosa en México. México: IMDOSOC (Col. Diálogo y crítica, 22)

MASFERRER KAN, Elio (2011) Pluralidad Religiosa en México. Cambios y proyecciones. México: Ed. Libros de la Araucaria.

MENÉNDEZ RODRÍGUEZ, Hernán (1995) Iglesia y Poder. México: Ed. Nuestra América / CNCA.

MOLINA HERNÁNDEZ, José Luis (2003) "Configuración regional del territorio religioso en México, 1950-2000”, Frontera Norte, vol. 15, núm. 30, pp. 91-119.

ROMERO DE SOLÍS, José Miguel (1994) El Aguijón del Espíritu. México: Ed. IMDOSOC.

SÁNCHEZ MEDAL, Ramón (1992) La Ley de Asociaciones Religiosas y Culto Público. Más espacios que cerrojos a la libertad religiosa. México: IMDOSOC (Col. Diálogo y crítica, 29).

TORO, Alfonso (1975) La Iglesia y el Estado en México (estudio sobre los conflictos entre el clero católico y los gobiernos mexicanos desde la independencia hasta nuestros días). México: Ed. Talleres Gráficos de la Nación, Ed. El Caballito. 